\title{
INTERLEUKIN-6 PLASMA LEVELS AND TUMOR SIZE IN CARDIAC MYXOMA
}

\author{
Rasjid Soeparwata, MD, ${ }^{a}$ Peter Poeml, StudMed, ${ }^{a}$ Christof Schmid, MD, ${ }^{a}$ Heinz Neuhof, MD, ${ }^{b}$ and Hans H. Scheld, \\ MD, ${ }^{a}$ Muenster and Giessen, Germany
}

In a certain subset of patients with cardiac myxoma noncardiac, constitutional signs and symptoms that resemble autoimmune disease are observed, such as hypergammaglobulinemia, fever, autoantibodies, and elevated erythrocyte sedimentation rate (ESR) and white blood cell count. The conditions that determine whether a patient becomes affected by these constitutional signs and symptoms are unknown. Interleukin-6 (IL-6), a multifunctional immunoregulatory cytokine that is involved in B-cell differentiation, T-cell activation, acute phase response, and hematopoiesis, has been found in these patients. ${ }^{1}$

In view of the pleiotropic nature of IL-6 and of cytokines in general we wanted to know whether there are further revealing markers that can be linked to the immunologic features of cardiac myxoma. We studied six patients with nonfamilial cardiac myxoma (ages 44 to 65 years; 1 man, 5 women). Diagnosis was established echocardiographically and confirmed histologically. None of the patients had evidence of systemic infection. Endotoxin levels were measured to rule out asymptomatic infection. All patients gave their informed consent.

We analyzed preoperative plasma samples for IL- $1 \beta$, IL-1 receptor antagonist (IL-1ra), IL-2, soluble IL-2 receptor (sIL-2r), IL-6, soluble IL-6 receptor (sIL-6r), IL-8, tumor necrosis factor-alpha (TNF- $\alpha$ ), TNF receptor I (TNF-rI) and II (TNF-rII), and granulocyte macrophage colony-stimulating factor with commercially available enzyme-linked immunosorbent assay kits (Quantikine, R \& D Systems, Minneapolis, Minn.). Endotoxin levels were determined with a modified chromogenic limulus amebocyte lysate test (Chromogenix, Mölndal, Sweden). The normal range of the mediator levels was provided by the manufacturer. It is noteworthy that $\mathrm{TNF}-\alpha$ values may give false-negative results because of the short half-life of this mediator.

Patient data and results are listed in Table I. Patients 1 through 4 did not have constitutional symptoms. Patient 1 ,

From the Department of Thoracic and Cardiovascular Surgery, Westfaelische Wilhelms-University of Muenster, Muenster, Germany, ${ }^{\mathrm{a}}$ and the Division of Clinical Pathophysiology and Experimental Medicine, Department of Internal Medicine, Justus-Liebig-University Giessen, Giessen, Germany. ${ }^{\mathrm{b}}$

Received for publication Dec. 28, 1995; accepted for publication April 1, 1996.

Address for reprints: Rasjid Soeparwata, MD, Department of Thoracic and Cardiovascular Surgery, Westfaelische Wilhelms-University of Muenster, Albert-Schweitzer-Str. 33, 48129 Muenster, Germany.

J Thorac Cardiovasc Surg 1996;112:1675-7

Copyright (C) 1996 by Mosby-Year Book, Inc.

$0022-5223 / 96 \$ 5.00+0 \quad \mathbf{1 2 / 5 4 / 7 3 9 1 6}$ who had a recurrent but noncomplex myxoma, and patient 2 were unobtrusive and all studied parameters were within normal ranges in these cases. Patient 3 had only a mild IL-6 elevation $(5.5 \mathrm{pg} / \mathrm{ml})$. In patient 4 there were two pathologic findings: an elevation of IL-6 level $(9.6 \mathrm{pg} / \mathrm{ml})$ and of sIL-6r level $(57 \mathrm{ng} / \mathrm{ml})$.

Patient 5, with increased gamma globulin values, with weight loss, anemia, increased ESR, and amaurosis fugax, showed an elevation of IL-6 level $(12.8 \mathrm{pg} / \mathrm{ml})$, and the sIL-6r level $(48 \mathrm{ng} / \mathrm{ml})$ was slightly increased. In addition, a major increase of IL- $1 \beta$ level $(10.4 \mathrm{pg} / \mathrm{ml})$ was present, and the only finding of increased level of granulocyte macrophage colony-stimulating factor $(5.6 \mathrm{pg} / \mathrm{ml})$ was noted.

Patient 6 also had constitutional symptoms (elevations of ESR, white blood cell count, and C-reactive protein); however, the pattern of mediators was different. The highest noticed IL-6 level was $15.9 \mathrm{pg} / \mathrm{ml}$ and there was an increased level of IL- $1 \beta(1.7 \mathrm{pg} / \mathrm{ml})$ and an outstanding high level of IL-1ra ( $2364 \mathrm{pg} / \mathrm{ml})$; furthermore, apart from the other cases, there was a mild increase in TNF- $\alpha$ (7.9 $\mathrm{pg} / \mathrm{ml})$, TNF-rI $(1.5 \mathrm{ng} / \mathrm{ml})$, and TNF-rII (3.2 ng/ml). This patient had lentiginosis and pigmented skin lesions and was obese, and operation was done under emergency conditions because of decompensation of the left side of the heart.

IL-1 $\beta$, IL-1ra, and IL-6 levels are depicted in Fig. 1. Levels of $\Pi \mathrm{L}-2$, sIL-2r, IL-8, and endotoxin were normal resp. negative in all cases.

We calculated an arbitrary index by multiplying the three dimensions of the tumor size, and there was a strong positive correlation of this index to the circulating IL-6 amount $(r=0.95, p<0.005$; Fig. 2$)$. Furthermore, a close correlation with TNF-rI $(r=0.87, p<0.05)$ became evident. However, there was no significant correlation with sIL-6r $(r=0.38, p=0.49)$. The threshold of tumor size index for constitutional symptoms was 50 to $150 \mathrm{~cm}^{3}$, inasmuch as all cardiac myxomas less than $50 \mathrm{~cm}^{3}$ were asymptomatic and both myxomas greater than $150 \mathrm{~cm}^{3}$ occurred with constitutional symptoms.

To date, nine cases of cardiac myxoma with elevated systemic IL-6 levels have been reported in the literature: two of them presented without ${ }^{2-6}$ and seven with constitutional symptoms. ${ }^{6,7}$ In these seven patients and in our patients both constitutional symptoms and elevated serum IL-6 levels invariably returned to normal after resection of the tumor. ${ }^{2-6}$ Thus there is convincing evidence that the source of IL- 6 seems to be aberrant production by the tumor, which is substantially supported by the results of Seino, Ikeda, and Shimada, ${ }^{5}$ who found IL-6 messenger ribonucleic acid in all three cases they examined.

Interestingly, all myxoma cell culture supernatants that have been reported (12 cases) contained IL-6, independent of whether constitutional symptoms were present or 

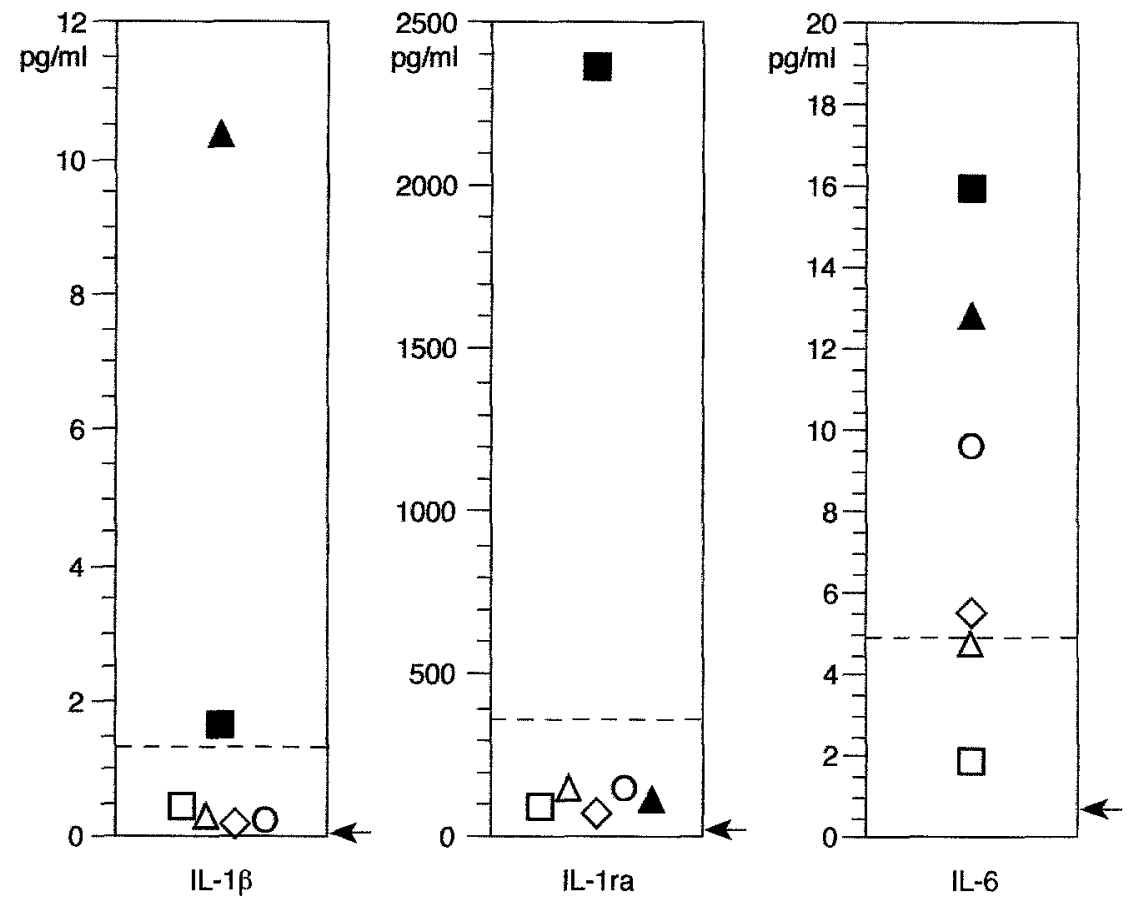

Fig. 1. IL-1 $\beta$, IL-1ra, and IL-6 levels in plasma of patients without (open symbols) and with (solid symbols) constitutional symptoms. Upper border of normal range is depicted by broken lines. Small black arrows indicate respective detection limits.

Table I. Patient data: cases are listed in order of $I L-6$ levels

\begin{tabular}{|c|c|c|c|c|c|c|}
\hline Case No. & $1 \square$ & $2 \Delta$ & $3 \diamond$ & 40 & $5 \mathbf{\square}$ & $6 \Delta$ \\
\hline Sex, age (yr) & $\mathrm{M}, 44$ & $F, 65$ & F, 56 & $\mathrm{~F}, 60$ & $\mathrm{~F}, 61$ & $F, 49$ \\
\hline Obstruction of blood flow & - & + & + & - & + & + \\
\hline Embolic phenomena & - & - & - & - & + & - \\
\hline Dyspnea & - & + & + & + & - & + \\
\hline Constitutional symptoms & None & None & None & None & $\begin{array}{l}\text { ESR elevated; } \\
\gamma \text {-globulins elevated; } \\
\text { weight loss; } \\
\text { anemia }\end{array}$ & $\begin{array}{l}\text { ESR elevated; } \\
\text { WBC count elevated; } \\
\text { CRP positive }\end{array}$ \\
\hline
\end{tabular}

Immunologic mediators
IL-1 $\beta$
IL-1ra
IL-2
sIL-2r
IL-6
sIL-6r
IL-8
$\mathrm{TNF} \alpha$
TNF-rI
TNF-rII
Endotoxin
GM-CSF

Site of tumor Size of tumor $(\mathrm{mm})$

-
-
-
-
-
-
-
-
-
-
-

LA (relapse) LA

$\begin{array}{ll}- & - \\ - & - \\ - & - \\ - & - \\ (+) & + \\ - & + \\ - & - \\ - & - \\ - & - \\ - & - \\ - & - \\ - & -\end{array}$

++
-
-
-
+
$(+)$
-
-
-
-
-
+

LA

LA

$\begin{array}{ll}- & + \\ - & - \\ - & - \\ - & + \\ + & + \\ + & - \\ - & - \\ - & - \\ - & + \\ - & + \\ - & +\end{array}$

$60 \times 60 \times 40$
$+$

$++$

$-$

$-$

$+$

$-$

$(+)$

$+$

$+$

$-$

NR

$M$, male; $F$, female; -, normal/negative; + , positive; $W B C$, white blood cell; $C R P$, C-reactive protein; $G M$-CSF, granulocyte macrophage colony-stimulating factor; $N R$, not recorded; $L A$, left atrium. 


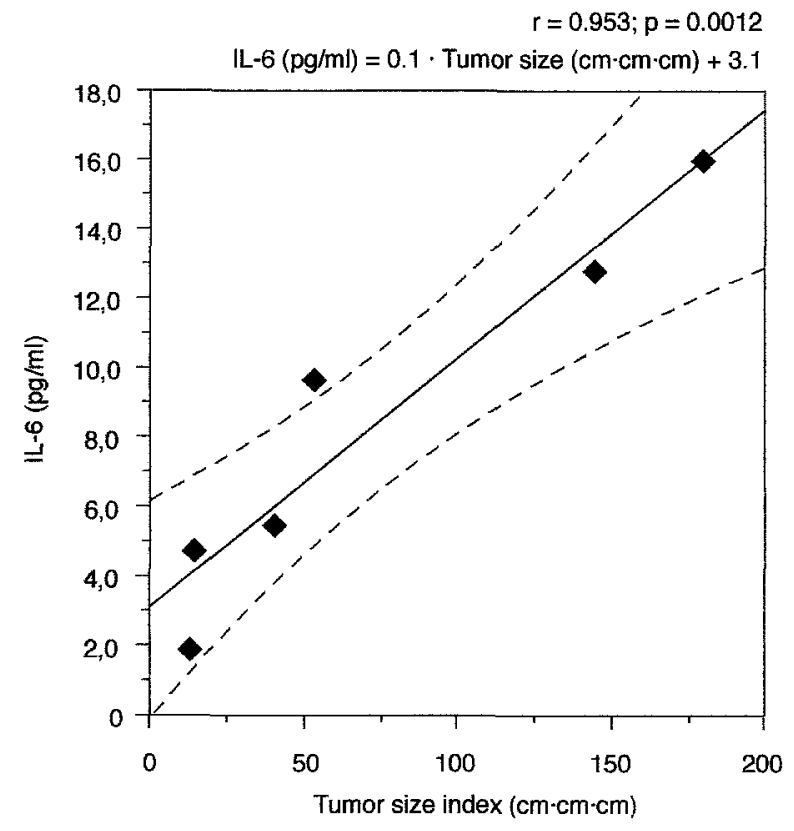

Fig. 2. Plasma IL-6 level plotted against tumor size index, calculated as described in text. Regression line (solid line) and $95 \%$ confidence interval (broken lines) are shown.

not. ${ }^{1,2,6,7}$ Similar results were obtained when messenger ribonucleic acid was analyzed. ${ }^{5}$ From these observations one may conclude that IL-6 production is not an infrequent finding but rather a feature of every cardiac myxoma.

Why do constitutional symptoms develop in some patients and not in others? The physiologic level of IL-6 is estimated at 1 to $5 \mathrm{pg} / \mathrm{ml}$. According to our results it might well be that constitutional symptoms only manifest after IL-6 levels exceed a certain threshold. This could be settled around $9 \mathrm{pg} / \mathrm{ml}$, inasmuch as our patients were free of constitutional symptoms when the $\mathrm{LL}-6$ level was lower than $10 \mathrm{pg} / \mathrm{ml}$ (Fig. 1) and constitutional symptoms appeared with levels of $9 \mathrm{pg} / \mathrm{ml}$ and higher. ${ }^{2-7}$ However, two reported cases deviate from this: one with constitutional symptoms and an IL-6 level as low as $6 \mathrm{pg} / \mathrm{ml}^{5}$ and one with exceptionally high IL-6 levels ( $212 \mathrm{pg} / \mathrm{ml})$ but with no constitutional symptoms. ${ }^{6}$

Our results show that the amount of circulating IL-6 directly depends on the size of the tumor, that is, on the number of IL-6-producing myxoma cells (Fig. 2). Because we found a correlation between tumor size and constitutional symptoms, a significant concentration response relationship of the IL- 6 level with the development of constitutional symptoms might be proved in larger studies.

The mechanism by which IL- 6 mediates the effects is still unclear, but Hirano and associates ${ }^{1}$ suggested that IL-6 might elicit the formation of autoantibodies, because antinuclear autoantibodies have repeatedly been found in sera of those patients with high levels of IL-6. ${ }^{1-3,5}$

The interpretation of the overall mediator pattern seems to be unwarranted on the narrow basis of these few cases.

In summary, this study demonstrates a significant correlation between plasma IL-6 level and tumor size in patients with cardiac myxoma. Both IL-6 level and tumor size could be related to constitutional symptoms.

\section{REFERENCES}

1. Hirano T, Tetsuya T, Yasukawa $\mathrm{K}$, et al. Human B-cell differentiation factor defined by an anti-peptide antibody and its possible role in autoantibody production. Proc Natl Acad Sci 1987;84:228-31.

2. Jourdan M, Bataille R, Séguin J, Zhang XG, Chaptal PA, Klein B. Constitutive production of interleukin- 6 and immunologic features in cardiac myxomas. Arthritis Rheum 1990; 33:398-402.

3. Saji $T$, Yanagawa $E$, Matsuura $H$, et al. Increased serum interleukin-6 in cardiac myxoma. Am Heart J 1991;122:579-80.

4. Wiedermann CJ, Reinisch N, Fischer-Colbrie R, Vollmar AM, Herold M, Knapp E. Proinflammatory cytokines in cardiac myxomas. J Intern Med 1992;232:263-5.

5. Seino Y, Ikeda U, Shimada K. Increased expression of interleukin 6 mRNA in cardiac myxomas. Br Heart J 1993;69:565-7.

6. Sakamoto H, Sakamaki $T$, Wada A, Nakajima $T$, Kanda $T$, Murata K. Dexamethasone inhibits production of interleukin-6 by cultured cardiac myxoma cells. Am Heart J 1994;127: 704-5.

7. Kanda T, Sakamaki T, Murata K. A cardiac myxoma with interleukin- 6 production and cerebral metastasis. Int $\mathbf{J}$ Cardiol 1994;45:144-6. 